\title{
Analisis Pengaruh Modulasi Terhadap Bandwidth dan Power pada DVB-S2
}

\section{The Analysis of Modulation Effect on Bandwidth and Power on DVB-S2}

\author{
Anna Regiana Setiadi ${ }^{1}$, Imam Muhammadi Pradono Budi ${ }^{2}$, Solichah Larasati ${ }^{3}, *$ \\ 1,2,3 Program Studi S1 Teknik Telekomunikasi, Fakultas Teknik Telekomunikasi dan Elektro \\ Institut Teknologi Telkom Purwokerto \\ Jl. D.I Panjaitan No. 128, Purwokerto 53147, Jawa Tengah, Indonesia \\ 3,*Penulis korespondensi: laras@ittelkom-pwt.ac.id \\ 116101122@ittelkom-pwt.ac.id, 2imam@ittelkom-pwt.ac.id
}

Received on 30-01-2020, accepted on 20-10-2020, published on 17-07-2020

\begin{abstract}
Abstrak
Perkembangan sistem TV broadcast sudah menggunakan teknologi komunikasi satelit, salah satunya menggunakan teknologi direct to home (DTH). Standar TV digital yang digunakan dalam penelitian ini adalah DVBS2 (Digital Video Broadcasting Satellite - Second Generation) menggunakan frekuensi Ku Band. Penelitian ini bertujuan untuk mengetahui bagaimana kualitas link transmisi DVB-S2 berdasarkan pemakaian bandwidth dan power via satelit Measat 3B. Optimalisasi bandwidth dan power dilakukan dengan menggunakan teknik modulasi QPSK, 8PSK, dan 16QAM serta nilai forwad error coding (FEC). Agar mencapai kondisi optimal pada link transmisi DVB-S2 maka dilakukan perhitungan link budget pada masing - masing teknik modulasi dengan mempertimbangkan nilai FEC dan nilai BER sesuai dengan standar ITU dan standar penyiaran DVB-S2 (ETSI 302 307). Berdasarkan hasil penelitian modulasi yang layak digunakan pada DVB-S2 adalah modulasi 8PSK dengan 8/9 dikarenakan pada modulasi ini menghasilkan nilai bandwidth dan nilai $\mathrm{C} / \mathrm{N}$ yang cukup besar serta nilai Eb/No dan BER yang sesuai dengan standart yang diharapkan. Hal ini ditunjukan dengan nilai bandwidth pada modulasi 8PSK 8/9 adalah menghasilkan nilai Eb/No $13,67753 \mathrm{~dB}$ dengan BER 8,75844-08, sehingga kualitas sinyal yang diterima sangat baik.
\end{abstract}

Kata Kunci: Bandwidth, DVB-S2, Ku Band, Link Budget, Measat 3B, Modulasi, Power.

Abstract

The development of broadcast TV systems already uses satellite communication technology, one of which directly uses home (DTH) technology. The digital TV standard used in this research is DVB-S2 (Digital Video Broadcasting Satellite - Second Generation) using Ku Band frequency. This study aims to determine how the quality of the DVBS2 transmission link is based on bandwidth and power usage via the Measat 3B satellite. The optimization of bandwidth and power is carried out using the QPSK, 8PSK, and 16QAM modulation techniques and the forward error coding (FEC) value. Calculating the link budget for each modulation technique is necessary by considering the FEC and BER values following ITU standards and DVB-S2 broadcasting standards (ETSI 302 307) to achieve optimal conditions on the DVB-S2 transmission link. Based on the research results, the proper modulation used in DVB-S2 is 8 PSK modulation with $8 / 9$. This modulation produces a reasonably large bandwidth and $\mathrm{C} / \mathrm{N}$ value, and the Eb/No and BER values are by the expected standard. The bandwidth value indicates this in 8PSK 8/9 modulation, which produces an Eb/No value of $13.67753 \mathrm{~dB}$ with a BER of 8.75844-08, so the received signal quality is excellent.

Keywords: Bandwidth, DVB-S2, Ku Band, Link Budget, Measat 3B, Modulation, Power. 


\section{Pendahuluan}

Perkembangan teknologi digital di bidang telekomunikasi menujukan perkembangan yang sangat pesat. Jaringan satelit dapat digunakan untuk aplikasi multimedia seperti streaming, suara, video dan siaran televisi. Media penyiaran televisi merupakan salah satu sarana informasi yang berisi program, edukasi, berita, hiburan, promosi serta dakwah yang masih banyak digunakan bagi masyarakat Indonesia. Teknologi direct to home (DTH) adalah proses penyiaran televisi satelit dengan antena pribadi di rumah masingmasing. Teknologi ini dikembangkan untuk bersaing dengan layanan distribusi TV kabel lokal dengan menyediakan sinyal satelit berkualitas lebih tinggi dengan lebih banyak saluran [1].

DVB project kini mengelola sebuah standar internasional televisi digital yaitu DVB-S2 (Digital Video Broadcasting-Second Generation) dimana DVB-S2 merupakan suksesor dari sistem sebelumnya yaitu DVB-S [2]. Sistem transmisi sinyal DVB-S merupakan pilihan terbaik di Indonesia mengingat Negara kepulauan dengan area yang cukup luas dan tidak semua bisa terjangkau oleh jaringan terestrial. Penggunaan transmisi sinyal DVB-S, bandwidth yang dialihkan menjadi lebih kecil dibandingkan dengan transmisi sinyal analog, sehingga menghemat dalam sewa bandwidth [3].

Frekuensi Ku Band berada direntang $11 \mathrm{GHz}$ sampai $14 \mathrm{GHz}$, satelit dengan frekuensi ini memiliki jangkauan frekuensi yang lebih tinggi dibandingkan dengan frekuensi C Band. Penggunaan frekuensi di atas $10 \mathrm{GHz}$ redaman akibat curah hujan cukup tinggi, hal ini akan berpengaruh terhadap kualitas sinyal yang akan dikirim maupun diterima. Namun penggunaan frekuensi dibbawah $10 \mathrm{GHz}$ redaman akibat curah hujan sangat kecil sehingga dapat diabaikan[4].

Parameter utama yang harus diperhitungkan dalam komuniakasi satelit adalah bandwidth dan power karena ketersediaan kedua parameter tersebut bersifat limited. Untuk mencapai suatu kualitas link yang diharapkan, memerlukan power yang memadai dan bandwidth yang sesuai maka diperlukan pemanfaatan teknik modulasi dan pengkodean yang tepat agar tidak terjadi pemborosan [5].

Untuk mengatasi permasalahan tersebut, maka dilakukan analisis terhadap kualitas link yang paling optimal dalam sebuah jaringan digital TV broadcast satelit. Standar TV satelit yang digunakan dalam penelitian ini adalah DVB-S2. Analisis dilakukan dengan menghitung link budget pada sisi uplink dan downlink, serta pemilihan modulasi dan FEC yang tepat agar tidak terjadi pemborosan dalam pemakaian bandwidth dan power. Teknik modulasi yang digunakan dalam penelitian ini yaitu QPSK, 8PSK, dan 16QAM dilihat dari nilai FEC sehingga menghasilkan kondisi optimum.

\section{DASAR TEORI}

\section{A. Sistem Komunikasi Satelit}

Dalam menjalankan sistem komunikasi satelit terdapat dua elemen yang menjadi dasar dan berperan di dalamnya yaitu stasiun bumi (Ground segment) dan satelit (Space segment). Gambar 1 memperlihatkan tentang konfigurasi sistem komunikasi satelit[6] 




Gambar 1 Sistem Komunikasi Satelit

\section{B. Direct to Home (DTH)}

Direct to Home atau DTH didefinisikan sebagai proses penyiaran televisi satelit dengan penggunaan antena parabola pribadi di rumah masing-masing. Teknologi ini dikembangkan untuk bersaing dengan layanan distribusi TV kabel lokal dengan menyediakan sinyal satelit berkualitas lebih tinggi dengan lebih banyak saluran. Penyedia layanan akan menyiarkan program kepada pelanggan sesuai paket yang ditetapkan. Tidak seperti pemrograman sebelumnya, sekarang siaran provider sepenuhnya digital, yang berarti memiliki kualitas gambar dan suara stereo yang tinggi. Terdapat lima komponen utama untuk mentransmisikan dan menerima jaringan yaitu : pusat penyiaran, enkripsi dan transmisi, parabola dan penerima.[1]

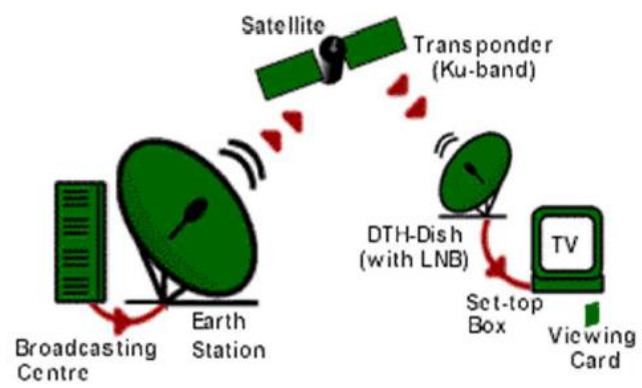

Gambar 2 Direct to Home

\section{Digital Video Broadcasting- Second Generation}

DVB-S2 adalah standar televisi digital yang telah dirancang sebagai pengganti DVB-S sistem dan diratifikasikan oleh ETSI (EN 3027 307). DVB-S2 dipertimbangkan untuk layanan siaran termasuk standar SDTV dan HDTV, akses internet, dan distribusi data konten.

Pada DVB-S generasi ke dua ini mengimplementasikan modulasi dan teknik pengkodean terbaru untuk meningkatkan kemampuan dari sistem broadcasting. Secara bertahap pula, standar DVB-S akan digantikan dengan DVB-S2 kedepannya. Pada DVB-S2 ditingkatkan teknik channel encode dan koreksi error sehingga menghasilkan sistem yang dapat memberikan layanan secara luas yang digabungkan dengan teknologi kompresi video terbaru. Dibandingkan dengan pendahulunya, DVB-S, DVB-S2 telah mengalami perkembangan antara lain [2]: 
1. Disediakan 4 mode modulasi, yaitu QPSK dan 8PSK yang ditujukan untuk aplikasi broadcast pada satelit non linear, 16APSK dan 32 APSK yang ditujukan untuk aplikasi profesional seperti pengumpulan berita dan layanan interaktif.

2. DVB-S2 menggunakan skema Forward Error Correction (FEC), sebuah parameter yang memungkinkan untuk memperoleh kinerja tinggi meskipun berada pada level noise dan interferensi yang tinggi.

3. Adaptive Coding and Modulation (ACM), sebuah teknologi yang memungkinkan perubahan parameter transmisi setiap frame berdasarkan kondisi tertentu. Teknologi ini ditujukan untuk layanan interaktif dan aplikasi profesional point-to-point.

\section{Teknik Modulasi}

Modulasi merupakan perubahan parameter dari sinyal carier menjadi sinyal informasi, Pada transmisi sinyal informasi digital modulator merupakan pengubah informasi menjadi suatu gelombang (sinyal) analog. Tujuan diberikannya modulator adalah untuk mempermudah pengiriman informasi. Sistem modulasi digital memiliki 3 teknik modulasi yang paling mendasar yaitu modulasi Amplitudo Shift Keying (ASK), Frekuensi Shift Keying (FSK), dan Phase Shift Keying (PSK).

\section{E. Bandwidth Calculation}

Bandwidth merupakan fungsi dari kecepatan informasi, FEC, jumlah bit dalam satu simbol $(m)$ dan roll of factor $(\alpha)$. Bandwidth dapat berdampak pada kecepatan transmisi. Data dalam jumlah besar dapat menempuh saluran yang mempunyai bandwidth kecil lebih lama dibandingkan melintasi saluran yang mempunyai bandwidth yang besar. Bit rate menyatakan jumlah bit informasi yang masuk sebagai input modem tiap detik. Dalam transmisi digital biasanya disertai pengkodean yang berfungsi untuk deteksi dan koreksi kesalahan serta memperbaiki BER system karena BER secara langsung menunjukkan kesalahan yang terjadi pada transmisi digital. [5]

Transimission rate (TR) merupakan jumlah data yang ditransmisikan dalam jangka waktu tertentu, biasanya bit per second, sedangkan Symbol Rate $(S R)$ merupakan .Untuk mengetahui besarnya Transmission Rate dan Symbol Rate dirumuskan pada Persamaan (1) dan Persamaan (2) sebagai berikut:

$$
T R=\frac{\text { Data Rate }+ \text { overhead }}{F E C}
$$

$S R=\frac{T R}{m}$

Adapun untuk mencari nilai bandwidth yang dipakai (BWocc) dan bandwidth yang dialokasikan $\left(B W_{A L L}\right)$ dapat menggunakan Persamaan (3) dan (4) dengan GB adalah guard band dan $\alpha$ adalah Roll of Factor $(0 \leq$ $\alpha \leq 1)$.

$$
B W_{O C C}=[S R x(1+\alpha)]
$$

$$
B W_{A L L}=B W_{O C C} \cdot(1+G B)
$$

Jumlah carrier untuk satu transponder dilihat dari segi bandwidth dapat dihitung menggunakan Persamaan (5) sebagai berikut:

$$
\text { Jumlah carrier }=\frac{B W_{x p d r}}{B W_{A L L}}
$$

Adapun untuk mengetahui prosentase bandwidth per carrier dapat dirumuskan pada Persamaan (6) sebagai berikut: 


$$
\%\left(\frac{B W}{\text { Carrier }}\right)=\left[\frac{\left[\left(B W_{A L L}\right)(H z)\right]}{\left[\left(B W_{x p d r}\right)(H z)\right]}\right] \cdot 100 \%
$$

Prosentasi bandwidth merupakan bandwidth per carrier yang dapat diketahui dari Bandwidth allocated dengan bandwidth pada keseluruhan dalam satu transponder. Adapun untuk mengetahui prosentase penggunaan power setiap carrier-nya dapat dirumuskan pada Persamaan (7) sebagai berikut :

$$
\%\left(\frac{\text { POWER }}{\text { Carrier }}\right)=\frac{\text { power terpakai }}{\text { power tersedia }} \cdot 100 \%
$$

Pada prosentase power ini dilakukan dengan membagi power yang digunakan dengan power yang tersedia pada satelit. Power yang tersedia untuk transponder disini adalah power pada saat saturasi dikurangi dengan output back off total.

\section{Metode Penelitian}

Penilitian ini menggunakan metode studi kasus dengan mengacu pada teori dasar telekomunikasi yaitu mengenai perhitungan link budget pada satelit. Penelitian ini dilakukan pada link komunikasi satelit stasiun bumi Kota Bogor dan stasiun bumi Kota Timika, Papua.

\section{A. Alur Penelitian}

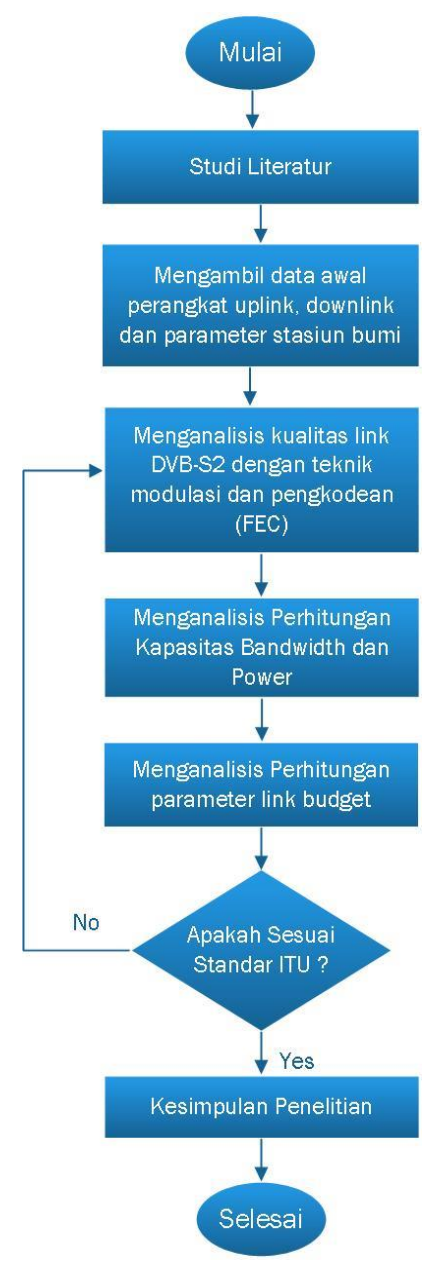

Gambar 3 Flowchart 


\section{B. Perhitungan Bandwidth dan Power}

Pada perhitungan bandwidth dilakukan dengan menghitung bandwidth occupied, bandwidth allocated pada masing masing pasangan modulasi dan code rate. Sedangkan perhitungan dari segi power dengan melakukan perhitungan $\mathrm{C} / \mathrm{N}$ disisi uplink, disisi downlink serta $\mathrm{C} / \mathrm{N}$ total. Adapun hal-hal yang dapat menentukan nilai perhitungan di stasiun bumi diantaranya adalah diameter antenna, koordinat stasiun bumi, EIRP $_{\mathrm{SB}}$, Loss propagation, G/, K (konstanta Boltzmann) dan B (Bandwidth Allocated). Dalam hal ini untuk mengetahui suatu link komunikasi bersifat bandwidth limited maupun power limited maka perlu dilakukan perhitungan prosentasi BW percarrier pada Persamaan (6) dan perhitungan prosentasi power pada Persamaan (7).

\section{Perhitungan Parameter Kualitas Sinyal}

Parameter Eb/No merupakan salah satu parameter yang menyatakan kemampuan kinerja dari sistem komunikasi digital. Dalam penentuan kualitas sinyal yang akan diterima pada suatu komunikasi satelit ditentukan pada suatu perbandingan energi sinyal pembawa per bit per hertz yang diterima oleh terhadap derau thermal. Eb/No akan menentukan besarnya kecepatan kesalahan bit yang disebut Bit Error Rate (BER).

Hubungan Eb/No dan BER dipengaruhi oleh jenis modulasi yang digunakan. Semakin besar Eb/No, semakin kecil harga bit error rate. Sehingga untuk memperkecil jumlah kesalahan bit pada data yang dikirim, adalah dengan Eb/No yang besar. Tetapi karena menjadi tidak ekonomis, maka perlu ditentukan kebutuhan Eb/No minimum akan tetapi mampu memenuhi BER yang sudah ditentukan dari layanan. Agar daya pancar mampu memenuhi Eb/No minimum, maka dilakukan dengan penerapan FEC.

\section{Perhitungan Link Budget}

\section{Gain Antena}

Gain atau penguatan adalah perbandingan antara daya pancar suatu antena terhadap antena refrensinya.

\section{Sudut Azimuth dan Elevasi}

Sudut Elevasi ( $€$ ) adalah sudut yang dihasilkan oleh arah utara sebenarnya dari titik yang akan kita pasang antenna dengan arah vertikal antara satelit dengan antena. Sudut azimuth (A) secara teoretis berada di antara 0 dan $360^{\circ}$, namun tergantung dari lokasi stasiun bumi dengan mengambil titik acuan pada titik subsatelit.

\section{Perhitungan Slant Range}

Slant Range (Daerah Kemiringan) merupakan perhitungan jarak antara stasiun bumi ke satelit. Kelengkungan bumi dan posisi stasiun bumi pada posisi lintang dan bujur berbeda antara satu dengan yang lainnya, hal ini akan mempengaruhi nilai slant range.

\section{Effective Isotropical Radiated Power (EIRP)}

EIRP merupakan besaran yang menyatakan kekuatan daya pancar antena, sehingga parameter ini merupakan hasil penjumlahan dari daya yang dipancarkan oleh antena dengan penguatan antena tersebut.

\section{Figure of Merit $(G / T)$}

Sensitifitas penerimaan (G/T) atau Receiver Figure of Merit adalah suatu satu cara untuk menentukan performansi sistem penerimaan dalam komunikasi satelit.

\section{Carrier to Noise Power Ratio (C/N)}

Carrier to Noise Power Ratio $(\mathrm{C} / \mathrm{N})$ merupakan perbandingan antara daya sinyal pembawa dengan daya derau yang diterima. Dalam sistem komunikasi satelit terdapat tiga buah jenis $\mathrm{C} / \mathrm{N}$, yaitu $\mathrm{C} / \mathrm{N}$ uplink, $\mathrm{C} / \mathrm{N}$ downlink dan $\mathrm{C} / \mathrm{N}$ total.

\section{7. $\mathrm{Eb} / \mathrm{No}$}


Parameter Eb/No merupakan salah satu parameter yangmenyatakan kemampuan kinerja dari sistem komunikasi digital. Dalam penentuan kualitas sinyal yang akan diterima pada suatu komunikasi satelit ditentukan pada suatu perbandingan energi sinyal pembawa per bit per hertz yang diterima oleh terhadap derau thermal.

\section{Forward Error Correction (FEC)}

FEC digunakan pada transmisi digital untuk memperbaiki kesalahan dan mengoptimalkan kapasitas transponder, karena penerima akan mendeteksi kesalahan dan mengoreksi kesalahan tersebut tanpa membutuhkan transmisi ulang.

\section{Bit Error Rate (BER)}

BER adalah perbandingan antara jumlah bit informasi yang diterima secara tidak benar dengan jumlah bit informasi yang ditransmisikan pada selang waktu tertentu.

\section{HASIL DAN ANALISIS}

\section{A. Ananlisi Pengaruh Modulasi Terhadap Bandwidth}

Dalam penelitian ini data yang dikirim berupa video MPEG-4 sebesar $6000 \mathrm{kbps}$. Dimana data rate 6000 kbps sudah dapat menghasilkan gambar video dengan resolusi yang baik sesuai dengan standar H.264. Modulasi yang digunakan dalam penelitian ini yaitu modulasi QPSK, 8PSK, dan 16QAM dengan DEC yang dipakai masing-masing modulasi yaitu sebesar 3/4, 5/6, dan 8/9. Roll of factor yang digunakan sebesar 20\% dimana sudah memenuhi standar DVB-S2 yaitu ETSI EN 302 307-1.

Tabel 1 Hasil Perhitungan Bandwidth

\begin{tabular}{|l|c|c|c|c|c|} 
Modulation & FEC & $\begin{array}{c}\text { TR } \\
(\mathbf{K b p s})\end{array}$ & $\begin{array}{c}\text { SR } \\
(\mathbf{K s p s})\end{array}$ & $\begin{array}{c}\text { BWocc } \\
(\mathbf{K H z})\end{array}$ & $\begin{array}{c}\text { BWall } \\
(\mathbf{K H z})\end{array}$ \\
\hline QPSK & $3 / 4$ & 8400 & 4200 & 5040 & 6048 \\
\hline QPSK & $5 / 6$ & 7560 & 3780 & 4536 & 5443,2 \\
\hline QPSK & $8 / 9$ & 7087,5 & 3543,75 & 4252,5 & 5103 \\
\hline 8 -PSK & $3 / 4$ & 8400 & 2800 & 3360 & 4032 \\
\hline 8-PSK & $5 / 6$ & 7560 & 2520 & 3024 & 3628 \\
\hline 8-PSK & $8 / 9$ & 7087,5 & 2362,5 & 2835 & 3402 \\
\hline 16-QAM & $3 / 4$ & 8400 & 2100 & 2520 & 3024 \\
\hline 16-QAM & $5 / 6$ & 7560 & 1890 & 2268 & 2721,6 \\
\hline 16-QAM & $8 / 9$ & 7087,5 & 1771,875 & 2126,25 & 2551,5 \\
\hline
\end{tabular}

Berdasarkan Tabel 1, nilai dari kecepatan transmisi (TR) bergantung pada nilai FEC. Pada FEC 3/4 menghasilkan TR sebesar $8400 \mathrm{Kbps}$, sedangkan pada FEC 5/6 menghasilkan nilai TR sebesar $7560 \mathrm{Kbps}$ dan pada FEC 8/9 menghasilkan nilai TR 7087,5 Kbps. Hal ini menunjukan bahwa semakin besar nilai FEC maka nilai kecepatan transmisi semakin kecil. Sedangkan nilai Symbol Rate (SR) didapatkan dari hasil nilai TR dibagi dengan nilai indeks modulasi. Semakin tinggi nilai indeks modulasinya maka hasil nilai SR akan semakin kecil. Hal ini dibuktikan dengan pada modulasi QPSK dengan FEC 3/4 menghasilkan nilai SR $4200 \mathrm{Ksps}$, sedangkan pada modulasi 16QAM dengan FEC 8/9 menghasilkan nilai SR 1771,875 Ksps.

Dari data diatas menunjukan bahwa dari ketiga modulasi yang digunakan, modulasi yang menghasilkan nilai bandwitdh paling besar adalah modulasi QPSK. Dengan nilai bandwidth occupied dan bandwidth allcocated sebesar $5040 \mathrm{KHz}$ dan $6048 \mathrm{KHz}$ dengan nilai FEC yang digunakan adalah 3/4. Sedangkan nilai bandwidth paling kecil diantara ketiga modulasi tersebut adalah modulasi 16QAM. Dengan nilai bandwidth occupied dan bandwidth allocated sebesar 2126,25 KHz dan 2551,5 KHz dengan nilai FEC yang digunakan adalah 8/9. Pada setiap modulasi mempunyai nilai indeks modulasi yang berbeda, dimana hal ini akan mempengaruhi dari segi bandwidth. Semakin tinggi nilai indeks modulasi maka bandwidth akan semakin kecil dan begitu pula sebaliknya semakin rendah nilai indeks modulasi maka bandwidth kan semakin lebar. Sama halnya dengan nilai FEC semakin besar nilai FEC maka bandwidth akan semakin kecil. Oleh karena itu pemilihan modulasi dan FEC harus dipertimbangkan karena akan mempengaruhi penggunaan bandwidth. Perbandingan bandwidth allocated dan bandwidth occupied dapat dilihat pada Gambar 4. 


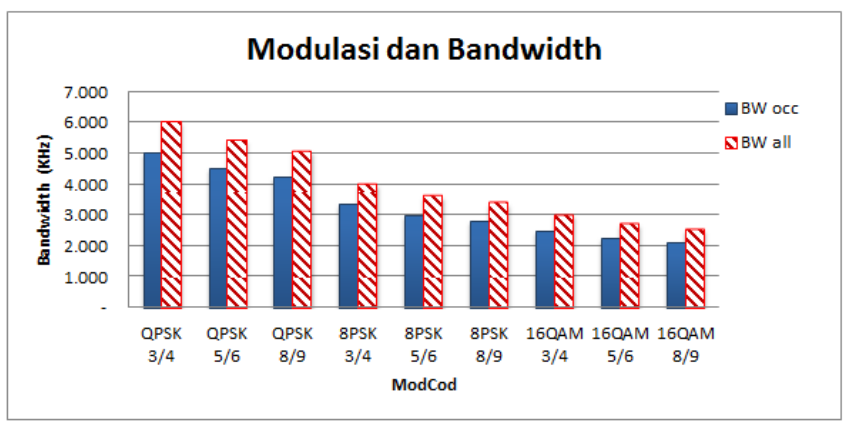

Gambar 4 Perbandingan Bandwidth dengan Modulasi

Gambar 4 menunjukan gambar grafik menurun, hal tersebut menunjukan bahwa pada bandwidth occupied dan bandwidth allocated menghasilkan nilai semakin kecil berbanding dengan penggunaan tingkat modulasi yang semakin tinggi. Pada bandwidth occupied dan bandwidth allocated terdapat perbedaan hasil dikarenakan terdapat guardband sebesar $20 \%$. Sehingga grafik diatas menunjukan nilai bandwidth allocated lebih besar nilainya dibandingkan dengan bandwidth occupied.

\section{B. Analisis Pengaruh modulasi terhadap $\mathbf{C} / \mathbf{N}$}

Berdasarkan Tabel 2 nilai C/N paling besar terdapat pada modulasi 16QAM yaitu 18,11450 dB dengan nilai FEC sebesar 8/9, sedangkan QPSK menghasilkan nilai C/N paling kecil yaitu 14,36634 dB dengan nilai FEC 3/4. Meskipun dalam segi bandwidth, modulasi QPSK ini memiliki bandwidth yang paling besar di antara modulasi yang lain, akan tetapi modulasi tersebut kurang optimal dari segi power. Sementara itu untuk modulasi 16QAM memiliki nilai $\mathrm{C} / \mathrm{N}$ total yang paling tinggi diantara modulasi lainya. Dengan nilai tertinggi adalah 18,11450 dB dan menggunakan nilai FEC sebesar 8/9. Akan tetapi modulasi tersebut kurang optimal dari segi bandwidth. Dimana untuk bandwidth dengan menggunakan nilai FEC 8/9 pada modulasi 16QAM ini memiliki bandwidth terkecil diantara modulasi lainya. Oleh karena itu jika dilihat dari kedua aspek maka tersebut maka modulasi 8PSK adalah modulasi yang paling optimal dibangingkan dengan modulasi QSPK dan 16QAM. Hal ini dikarenakan pada modulasi 8PSK memiliki bandwidth yang tidak terlalu kecil serta nilai $\mathrm{C} / \mathrm{N}$ total pun yang tidak terlau kecil.

Tabel 2 Hasil Perhitungan Parameter kualitas sinyal.

\begin{tabular}{|l|c|c|c|c|}
\hline Modulation & FEC & $\begin{array}{c}\text { C/N } \\
(\mathbf{d B})\end{array}$ & $\begin{array}{c}\text { Eb/No } \\
(\mathbf{d B})\end{array}$ & BER \\
\hline QPSK & $3 / 4$ & 14,36634 & 12,93967 & $1,88330 \times 10^{-7}$ \\
\hline QPSK & $5 / 6$ & 14,82392 & 13,39724 & $1,17125 \times 10^{-7}$ \\
\hline QPSK & $8 / 9$ & 15,10420 & 13,66753 & $8,75844 \times 10^{-8}$ \\
\hline 8 -PSK & $3 / 4$ & 16,12725 & 12,93967 & $1,88330 \times 10^{-7}$ \\
\hline 8-PSK & $5 / 6$ & 16,58483 & 13,39724 & $1,17125 \times 10^{-7}$ \\
\hline 8-PSK & $8 / 9$ & 16,86511 & 13,66753 & $8,75844 \times 10^{-8}$ \\
\hline 16-QAM & $3 / 4$ & 17,37664 & 12,93967 & $1,88330 \times 10^{-7}$ \\
\hline 16-QAM & $5 / 6$ & 17,83421 & 13,39724 & $1,17125 \times 10^{-7}$ \\
\hline 16-QAM & $8 / 9$ & 18,11450 & 13,66753 & $8,75844 \times 10^{-8}$ \\
\hline
\end{tabular}




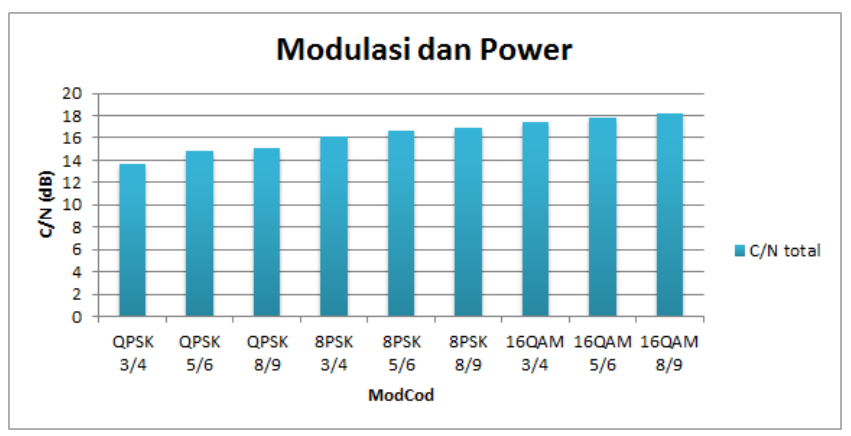

Gambar 5 Perbandingan $C / N$ dengan Modulasi

Hasil perbandingan modulasi dengan nilai $\mathrm{C} / \mathrm{N}$ dapat dilihat pada Gambar 5. Berdasarkan tersebut menunjukan bahwa gambar grafik meningkat. Berdasarkan hal ini dapat disimpulkan bahwa semakin tinggi teknik modulasi dan FEC yang digunakan maka membutuhkan power yang semakin besar. Hal ini dikarenakan semakin besar bandwidth yang dipakai akan menghasilkan $\mathrm{C} / \mathrm{N}$ total semakin kecil. Dalam hal ini menunjukan bahwa bandwidth yang besar belum tentu menjamin kualitas link yang bagus

\section{Pengaruh modulasi terhadap Eb/No}

Pemilihan teknik modulasi pada satelit Measat 3B harus mempertimbangkan beberapa aspek. Bandwitdh dan power merupakan parameter terpenting dalam pemilihan teknik modulasi. Nilai Eb/No menjadi tolak ukur performansi dari suatu modulasi. Performansi sistem komunikasi satelit di Transvision akan dianalisa berdasarkan kebutuhan Eb/No receiver stasiun bumi penerima agar sinyal memiliki BER yang berada dalam ambang batas. Treshold $\mathrm{Eb} / \mathrm{No}$ receiver standar yaitu sebesar $10 \mathrm{~dB}$ dengan nilai BER minimum $10^{-}$ ${ }^{6}$. Pada modulasi 8PSK nilai Eb/No yang didapatkan masih berada dalam ambang batas dan menghasilkan BER yang lebih rendah dari $10^{-6}$. Hal ini terbukti dari hasil perhitungan Eb/No dan BER pada setiap pasangan modulasi dan code rate pada Tabel 4.2. Dengan demikian sistem komunikasi satelit link BogorTimika telah memenuhi syarat karena Eb/No diperoleh melewati ambang batas sehingga sinyal yang diterima berkualitas baik.

Berdasarkan Tabel 4.2 dapat dilihat bahwa nilai Eb/No terbesar pada FEC 8/9 sebesar 13,67753 dB menghasilkan BER terendah yaitu $8,75844 \times 10^{-8}$, sehingga dalam pentransmisian $10^{-8}$ hanya diperbolehkan 8 bit yang rusak. Sedangkan nilai Eb/No terkecil 12,93967 dB yaitu pada FEC 3/4 menghasilkan BER yaitu $1,88330 \times 10^{-7}$, sehingga dalam pentransmisian $10^{-7}$ hanya diperbolehkan 1bit saja yang rusak.

Nilai BER terbaik $8,75844 \times 10^{-8}$ yang didapatkan dari perhitungan yaitu pada FEC 8/9 dengan menghasilkan nilai BER lebih rendah dari standar yang diterapkan. Berdasarkan hal ini dapat disimpulkan bahwa semakin besar FEC dan indeks modulasi, maka nilai Eb/No juga akan semakin besar. Nilai Eb/No yang semakin besar dan untuk mencapai nilai BER yang rendah, dibutuhkan daya pancar yang semakin besar pula. Sehingga, semakin besar orde modulasi dan FEC code rate yang digunakan, maka daya pancar yang dibutuhkan juga akan semakin besar.

\section{Analisis Pemakaian Bandwidth dan Power}

Melihat dari hasil perhitungan diatas prosentase pemakaian bandwidth dan prosentase pemakaian power menyatakan bahwa pada modulasi 8PSK dengan FEC 8/9 mengalami kondisi power limited. Hal ini terjadi karena perbandingan prosentase power lebih besar daripada prosentase bandwidth. Jumlah carrier maksimum dalam satu transponder sebanyak 9 Buah.

\section{KESIMPULAN}

Berdasarkan ketiga teknik modulasi yang digunakan yaitu QPSK, 8PSK, dan 16QAM dengan masingmasing nilai FEC 3/4, 5/6, dan 8/9 modulasi yang paling optimal digunakan pada DVB-S2 adalah modulasi 8PSK dengan FEC 8/9. Modulasi 8PSK dengan FEC 8/9 menghasilkan nilai Eb/No sebesar 13,67753 dB

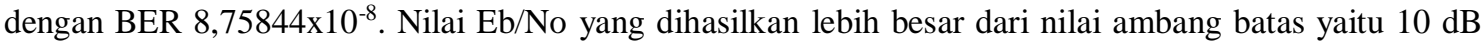


dan nilai BER yang dihasilkan lebih rendah dari standar DVB-S2 yang ditetapkan sebesar $10^{-6}$, sehingga kualitas sinyal yang diterima semakin baik. Perhitungan dari segi bandwidth dan power pada DVB-S2 menghasilkan kondisi power limited. Hal ini terjadi karena prosentase power lebih besar dari prosentase bandwidth. Jumlah carrier maksimum dalam satu transponder sebanyak 9 buah. Berdasarkan hasil analisis perbandingan power dan bandwidth dari ketiga modulasi diperoleh rata-rata bahwa semakin tinggi teknik modulasi maka semakin tinggi power yang digunakan sedangkan untuk optimalisasi power dan bandwidth maka digunakan FEC lebih besar.

\section{Daftar Pustaka}

[1] A. Tyagi, "DTH Technology," vol. 6, no. 17, pp. 1-4, 2018

[2] F. R. I. Krisnadi, P. Studi, and M. Teknik, "Optimalisasi Bandwidth dengan Menggunakan Modulasi 16APSK untuk Meningkatkan Mutu Siaran NEWS pada DVB-S2,” pp. 1-7.

[3] R. Nugroho, P. Studi, T. Elektro, and U. Nasional, "Perancangan Sistem Transmisi Sinyal DVB-S dan Terestrial UHF," vol. 16, no. 1, pp. 67-87, 2013.

[4] M. Pinem, "Analisa Perbandingan Diameter Antena Penerima Terhadap Kinerja Sinyal Pada Frekuensi Ku Band," Singuda ENSIKOM, vol. 6, no. 3, pp. 145-150, 2014.

[5] B. A. Purwanto, "Analisis Kinerja Penggunaan Modulasi QPSK, The Analysis Of Usage Performance Of QPSK, 8PSK, 16QAM Modulation On Telkom-1 Satellite," vol. 1, pp. 45-64, 2013.

[6] M. Khan and M. Ali, "Bandwidth and Power comparison for C/Ku Band Satellite Networks," J. Sp. Technol., vol. 5, no. 1, 2015. 